\title{
MUTATIONS AFFECTING FLAVONOID SYNTHESIS IN BARLEY
}

\author{
by
}

BARBRO JENDE-STRID

Department of Physiology, Carlsberg Laboratory, Gamle Carlsberg Vej 10, DK-2500 Copenhagen, Valby

Keywords: Anthocyanin, anthocyanidin, proanthocyanidin

The anthocyanin, anthocyanidin and proanthocyanidin content of 52 induced barley mutants with altered anthocyanin pigmentation in different organs of the plant has been investigated. Comparing these mutants no correlation between the amount of anthocyanin in the plant and the amount of proanthocyanidin in the dry grains is found. The proanthocyanidins of the lemma, palea, pericarp, testa and aleurone of Bonus, Foma, Kristina, Herta, Balder and 37 ant mutants yielded upon hydrolysis delphinidin and cyanidin. In 50 of the mutants belonging to at least 16 gene loci only anthocyanin synthesis is impaired. In mutant ant 13-13 a step in the biosynthetic pathway leading to anthocyanins, catechins and proanthocyanidins is blocked.

\section{INTRODUCTION}

The flavonoids comprise numerous and widespread natural plant products which are biosynthetically derived from the aromatic amino acids phenylalanine and tyrosine via the corresponding cinnamic acids. In plants the basic $\mathrm{C}_{15}$ skeleton probably results from a coupling of a cinnamate unit produced by the shikimic acid pathway with three acetate units (4). Once the $\mathrm{C}_{15}$ intermediate has formed it can be modified in a limited number of steps to yield the different flavonoid classes which differ in the oxidation state of the central ring.

Most of the brightly coloured blue and red plant pigments are anthocyanins, i.e., anthocyanidin glucosides containing one or more sugar residues and occasionally various other organic acid residues.

The proanthocyanidins are dimers or higher oligomers of flavan-3-ols. They yield anthocyanidins and catechins upon hydrolysis. Fruits have proved to be particularly rich in proan- 
B. JENDE-STRID: Mutations affecting flavonoid synthesis in barley

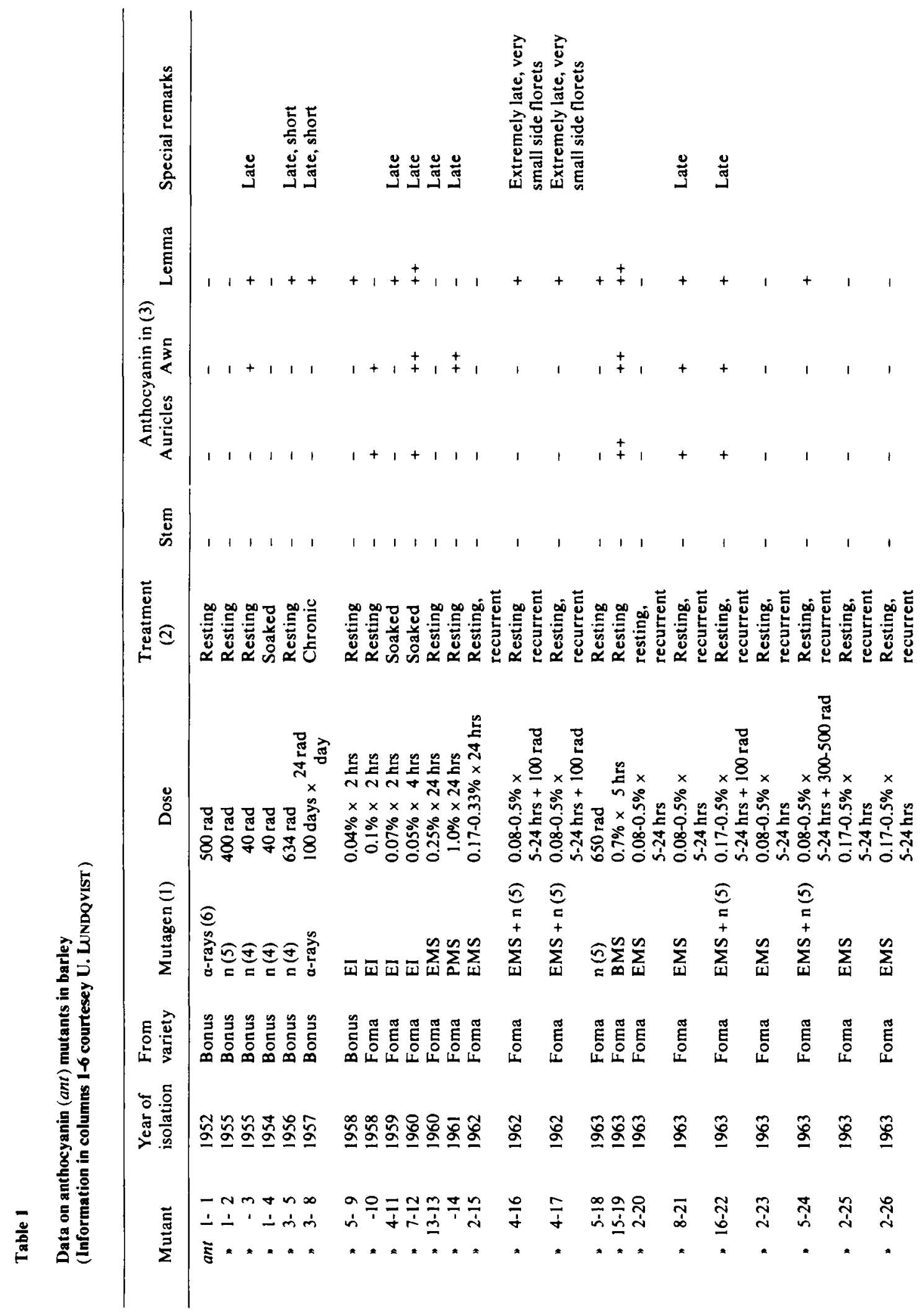




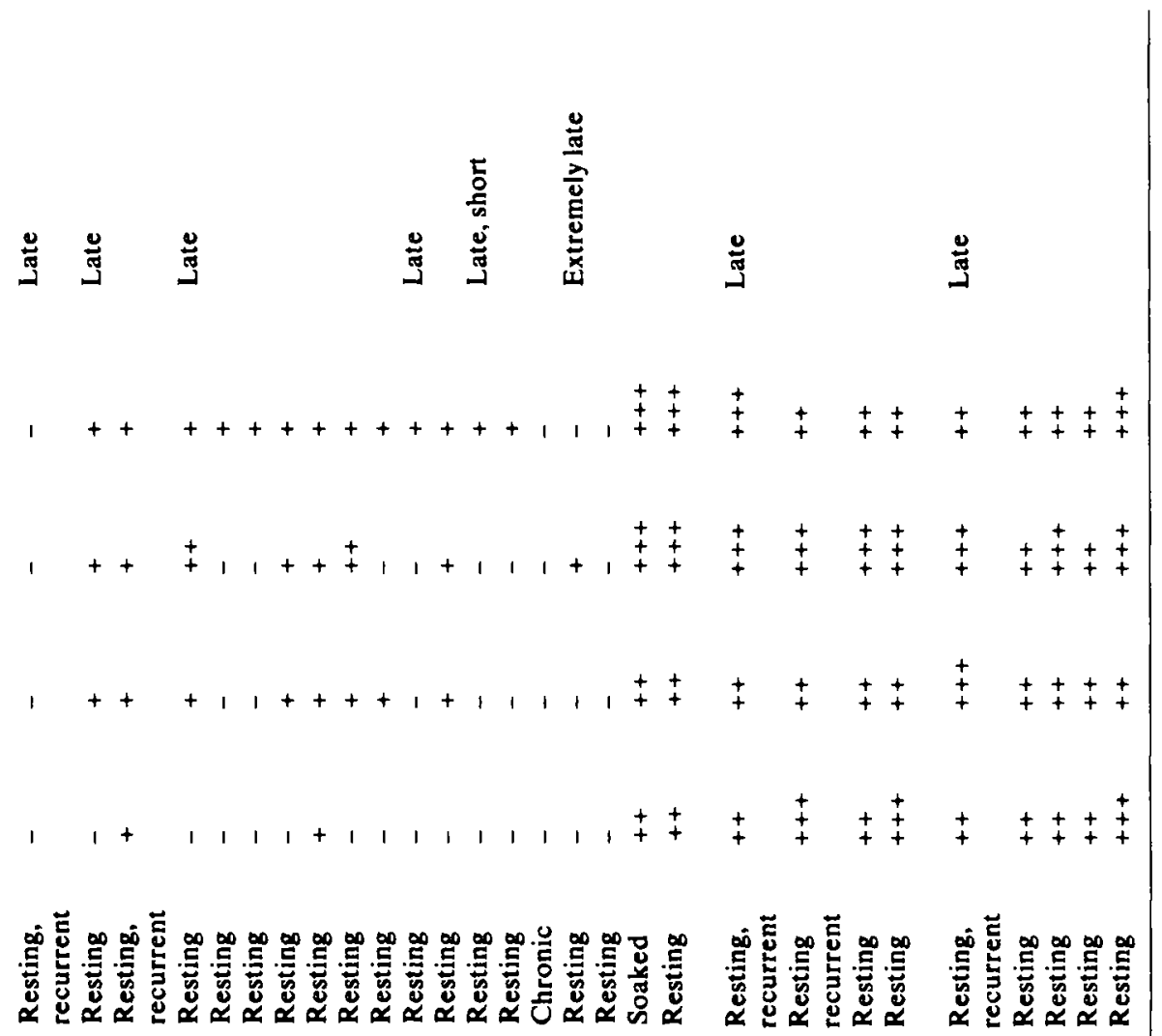

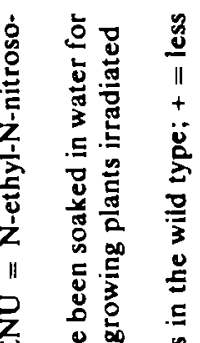

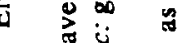

范

至 雚

पे

ปี

递官事 点

范吉

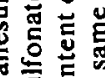

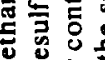

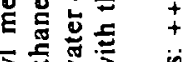

可豞

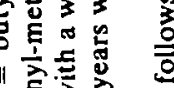

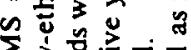

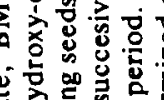

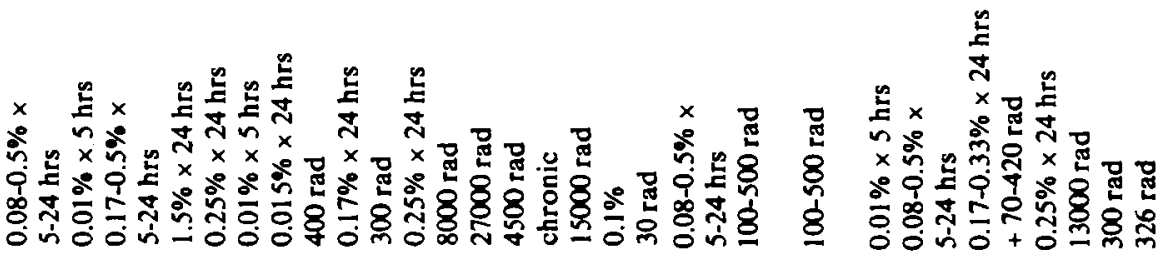

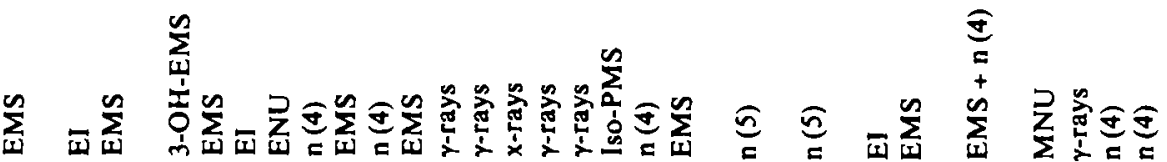

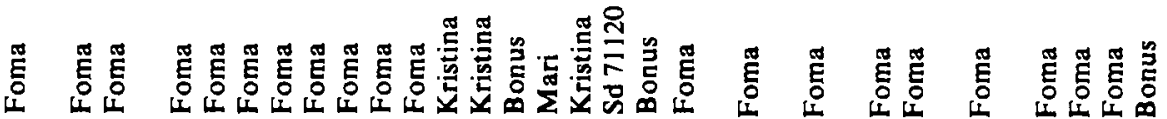

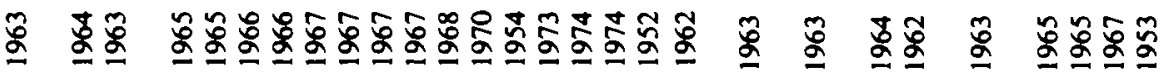

స

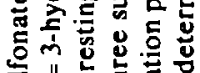

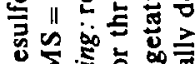

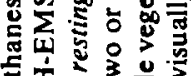

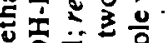

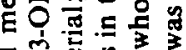

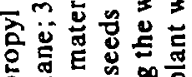

造要

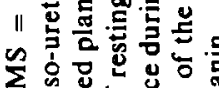

¿

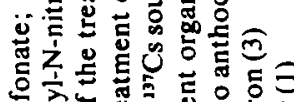

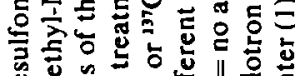

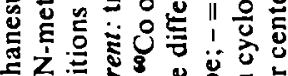

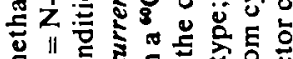

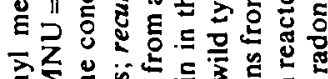

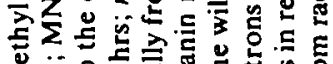

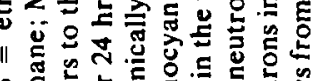

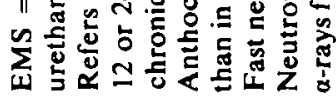

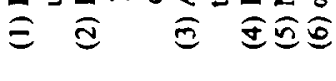


thocyanidins and unripe fruit and seeds contain more proanthocyanidins than ripe ones. The catechins (flavan-3-ols) occur together with the proanthocyanidins in the plant tissues (16). Both the catechins and the proanthocyanidins are unglucosylated.

The flavonoid content of a series of induced mutants in barley with altered anthocyanin pigmentation in various parts of the plant has been investigated. The anthocyanin content of the different organs of the plant was estimated visually and spectrophotometrically and the anthocyanidin and proanthocyanidin content of the dry grains analysed. Diallelic crosses among the mutants have so far identified 16 genes (ant) affecting flavonoid synthesis in barley (7). The two anthocyanin-free varieties Balder and Alva were found to be allelic with mutants in the ant 2 gene.

\section{MATERIALS AND METHODS}

\subsection{Plant material}

From the collection of artificially induced mutants kept at the Swedish Seed Association in Svalöv and the Institute of Genetics, University of Lund, 52 recessive gene mutants with altered anthocyanin pigmentation were kindly supplied by Professor ÁkE GUSTAFsSON and Mrs. UDDA LUNDQVIST together with detailed information on their origin. The gene symbol ant is used for genes in barley affecting the anthocyanin, anthocyanidin and proanthocyanidin content. The first figure following the symbol ant designates the locus and the second figure the allele (7). Data on the origin and characteristics of the 52 ant mutants are given in Table I. Of these mutants 41 are deficient in anthocyanin and 11 mutants develop more anthocyanin than their mother varieties. The majority of the mutants namely 37 were isolated from the variety Foma, 10 from Bonus, 3 from Kristina, one from Mari and one from Svalöv line 71120 . The mutants as well as their mother varieties were grown in observation plots. The amount of anthocyanin in the stems, auricles, awns and lemmas was visually estimated every week until harvest. Grains of the varieties Jet, Black African variety, Bonanza, Blue Indian variety, Gopal and Black Hulless, Balder and Herta were analysed for comparison.

\subsection{Anthocyanin determination}

Samples of auricles and awns ranging in fresh weight from $0.2-1.0 \mathrm{~g}$ were extracted with $1 \%$ $\mathrm{HCl}$ in methanol at $+4^{\circ} \mathrm{C}(17)$. The amount of anthocyanin was determined by measuring the difference in absorption at $530 \mathrm{~nm}$ of the extract before and after the addition of $\mathrm{H}_{2} \mathrm{O}_{2}$, which oxidizes the anthocyanin (15). A Zeiss PMQ III spectrophotometer was used.

\subsection{Anthocyanidin identification}

The procedure used for soaking and peeling samples of barley grains was based on the method of MULLICK and BRINCK (11). About 10 $\mathrm{g}$ of barley grains were soaked in water of about $0^{\circ} \mathrm{C}$ for four days. Then the grains were peeled manually and each was divided into three parts: (1) palea + lemma, (2) pericarp + testa, and (3) the aleurone layer with some adhering endosperm. Each sample was placed in $10 \mathrm{ml}$ of $1 \% \mathrm{HCl}$ in methanol and extracted at about $0^{\circ} \mathrm{C}$ for 48 hours. The solutions were decanted and washed with petroleum ether. Concentrated $\mathrm{HCl}$ was added to the extracts which were then placed on a boiling water bath for 30 minutes. The resulting anthocyanidins were extracted with iso-amylalcohol and spotted together with pure delphinidin, cyanidin, and pelargonidin (Calbiochem, Los Angeles, USA), on $0.25 \mathrm{~mm}$ Avicel SF cellulose (Serva Entwicklungslaboratorium, Heidelberg, FRG) thin layer chromatography plates. Two solvent systems were used for development: (1) propionic: propionic acid - formic acid - concentrated $\mathrm{HCl}$ - water, 2:5:1:6 v/v/v/v (10) and (2) formic: formic acid - concentrated $\mathrm{HCl}$ - water, 10:1:3, $\mathrm{v} / \mathrm{v} / \mathrm{v}$ (13). The chromatograms were examined under visible and UV-light as well as after treatment with ammonia fumes.

\subsection{Proanthocyanidin determination}

The proanthocyanidin content of the grains of ant mutants and their mother varieties was determined according to a method modified from HARRIS and RICKETTS (5) and described in v. WETTSTEIN et al. (18). The method of DADIC and MORRISON for simultaneous determination of proanthocyanidins and catechins in barley 
$(2,18)$ was used with four ant mutants and the varieties Black Hulless and Alva. DADIC's method is of advantage because it considers both the proanthocyanidin and the catechin content of the barley grains.

\section{RESULTS}

\subsection{Field observations}

The results of the field observations on anthocyanin pigmentation are summarized in Table I. The amount of anthocyanin in the stems, auricles, lemmas and awns varied with the developmental stage of the plant and the genotype. Maximal pigment concentration occurred first in the auricles, then in the awns and finally in the lemmas. When the plants turned yellow the amount of anthocyanin decreased, and by the time the plants were ripe anthocyanin was no longer detectable in most of the genotypes. Exceptional is mutant ant 1301, which has a strong red stem at harvest time.

Seven of the mutants contained more anthocyanin than the wild types in at least two of the investigated organs and four contained slightly more pigment at least in some years. A group of 41 mutants had reduced amounts of anthocyanin. Twelve of the ant mutants were anthocyanin-free throughout the growing season. Sixteen of the mutants were slower in development than the wild types and three others headed extremely late. Weather conditions, especially temperature had a strong influence on the amount and time of pigment formation.

Table II

Anthocyanidins and anthocyanin in the grain of different barley lines (Amounts are indicated as follows: ++ large, + small, - none).

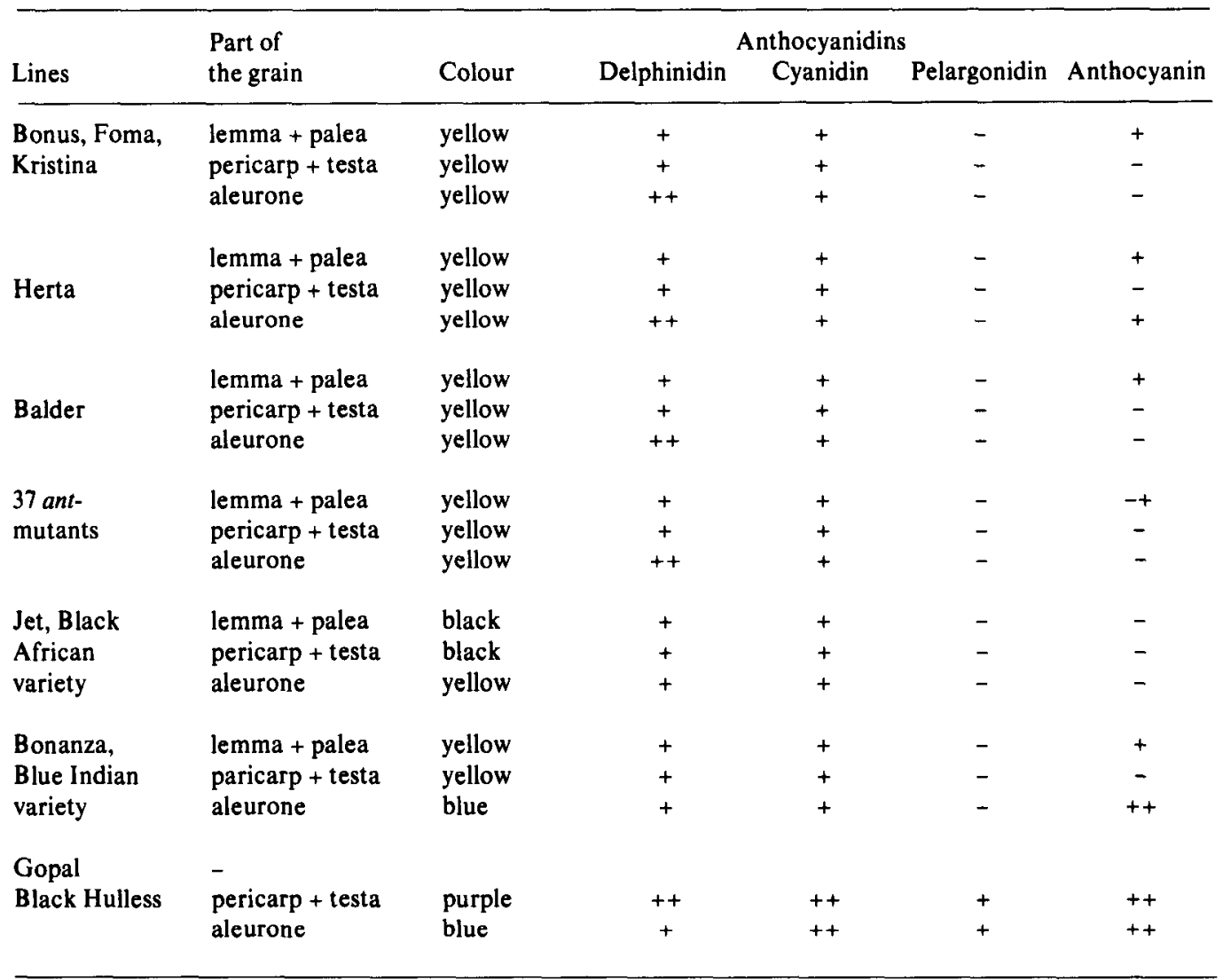


Table III

$\mathbf{R}_{\mathbf{f}}$ values of anthocyanidins isolated from barley.

Solvent system

\begin{tabular}{lcc} 
Anthocyanidin & Propionic & Formic \\
\hline Cyanidin & 0.26 & 0.44 \\
Cyanidin (standard) & 0.26 & 0.44 \\
Delphinidin & 0.13 & 0.28 \\
Delphinidin (standard) & 0.14 & 0.29 \\
Pelargonidin & 0.51 & - \\
Pelargonidin (standard) & 0.53 & - \\
\hline
\end{tabular}

\subsection{Anthocyanidins}

In Tables II and III are listed the anthocyanidins identified in the various parts of the grain with the aid of thin layer chromatography. The investigated barley varieties belong on the basis of the colour of the ripe grain to 4 groups: (A) yellow, (B) black, (C) blue and (D) purple. The results are in agreement with those of MULLICK et al. (12) who investigated 8 other barley varieties which include varieties with yellow (called white), black, blue, and purple grains.

(A) Foma, Bonus, Kristina and 37 analysed ant mutants all have yellow coloured lemma, palea, pericarp, testa, and aleurone. Balder, considered as an anthocyanin-free variety, and Herta, considered as very anthocyanin-rich also fall in this category. Before hydrolysis the extracts contained no anthocyanin and were light yellow in colour, except some extracts prepared from lemmas + paleas early in the autumn, which contained a very small amount of anthocyanin and were pale pink. In Herta the aleurone layer of some grains contained a small amount of anthocyanin. The distribution and concentration of the anthocyanidins released from the proanthocyanidins and the small amounts originating from the anthocyanins were undistinguishable in all these varieties. Extracts from lemma + palea, pericarp + testa and aleurone contained the anthocyanidins cyanidin and delphinidin. Most of the anthocyanidin was present in the aleurone layer with a little in the pericarp + testa and the lemma + palea. In both lemma + palea and pericarp + testa the concentrations of cyanidin and delphinidin were about the same whereas extracts from the aleurone layer contained approximately twice as much delphinidin as cyanidin.

(B) In the black varieties Jet and an unnamed African variety, delphinidin and cyanidin occurred in similar amounts as in the yellow lines. Since no anthocyanin was present in the black varieties all measured anthocyanidin in the extracts from lemma + palea, pericarp + testa and aleurone must have been released from proanthocyanidins. The black colour of the lemma and pericarp of these varieties is not attributable to anthocyanidin.

(C) In the blue varieties, Bonanza and an unnamed Indian variety, delphinidin and cyanidin occurred in the lemma + palea, pericarp + testa and aleurone layer. In both pericarp + testa and aleurone the concentrations of delphinidin and cyanidin were about the same. The blue varieties contain a small amount of anthocyanin in the lemma + palea, none in the pericarp + testa and much anthocyanin in the aleurone layer.

(D) The pericarp + testa and aleurone layer of the purple varieties Gopal and Black Hulless contained delphinidin and cyanidin and a third anthocyanidin, pelargonidin. In addition they differed from the other studied varieties by having more cyanidin. The grains of Gopal and Black Hulless were very purple. The pericarp + testa of Gopal was richer in anthocyanin than the aleurone layer. Black Hulless, on the other hand, had a blue very anthocyanin-rich aleurone layer and less pigment in the pericarp + testa. However, the amount of anthocyanin in the aleurone varied among the grains. Thus, in both varieties the anthocyanins contributed significantly to the amount of anthocyanidins observed.

\subsection{Proanthocyanidins}

Proanthocyanidins were determined with the modified HARRIS and RICKETTS method as well as the DADIC and MORRISON procedure in grains from lines distinct by their content of anthocyanins in the vegetative parts and from the variety Black Hulless with its high content of anthocyanin in the grain. (Tables IV and V). 
Table IV

Comparison of anthocyanin and proanthocyanidin content in different lines of barley.

\begin{tabular}{lcccc}
\hline & \multicolumn{2}{c}{$\begin{array}{c}\text { Anthocyanin OD/g } \\
\text { fresh weight }\end{array}$} & \multicolumn{2}{c}{$\begin{array}{c}\text { Proanthocyanidin in grain mg/100g } \\
\text { dry weight (HARRIS and RickETTs) }\end{array}$} \\
Genotype & Awns & Auricles & 1973 & 1974 \\
\hline Foma & & & & 161 \\
Bonus & 0.9 & 0.5 & 202 & 180 \\
Kristina & 1.0 & 0.5 & 217 & - \\
ant-1106 & 0.9 & 0.4 & 150 & 149 \\
ant-1201 & 13.5 & 0.5 & 175 & 170 \\
\hline
\end{tabular}

The amount of anthocyanin in the auricles and awns of Foma, Bonus and Kristina is very similar (Table IV). The proanthocyanidin content varied between 161 and $217 \mathrm{mg}$ per $100 \mathrm{~g}$ dry weight which is not considered significantly different. Mutant ant-1106 with its drastically increased anthocyanin content in the awns did not reveal a parallel increase in the proanthocyanidin content of the grain. Mutant ant-1201 which has an elevated content of anthocyanin in the awns and auricles likewise contained a standard amount of proanthocyanidin.

In Table $\mathrm{V}$ both proanthocyanidins and catechins are considered. The anthocyanin-rich grains of the variety Black Hulless show the highest total polyphenol content. If this dif- ference is significant it could be entirely due to the anthocyanin content of the grain. The mutants with reduced or non-detectable amounts of anthocyanin in the vegetative plant parts had in the grains a similar content of proanthocyanidin and catechin with the notable exception of ant 13-13 (18), which does not form significant amounts of proanthocyanidin and catechin.

It can be concluded from these observations that the content of anthocyanin can vary independently from that of proanthocyanidin.

For a more detailed analysis of the variation in proanthocyanidin content a large number of ant mutants has been studied as listed in Table VI. Of the mutants with an increased amount of

Table V

Proanthocyanidin and catechin content in the grain of 1976 determined according to the DADIC and MoRRISON method.

\begin{tabular}{|c|c|c|c|c|}
\hline Category & Genotype & $\begin{array}{l}\text { Mg proanthocyanidin } \\
\text { per } 100 \mathrm{~g} \text { dry weight }\end{array}$ & $\begin{array}{l}\text { Mg catechin per } \\
100 \text { g dry weight }\end{array}$ & $\begin{array}{l}\mathrm{Mg} \text { total polyphenols } \\
\text { per } 100 \mathrm{~g} \text { dry weight }\end{array}$ \\
\hline $\begin{array}{l}\text { Anthocyanin } \\
\text { in grain }\end{array}$ & $\begin{array}{l}\text { Black } \\
\text { Hulless }\end{array}$ & 228 & 206 & 434 \\
\hline $\begin{array}{l}\text { Mutants with } \\
\text { reduced amount } \\
\text { of anthocyanin } \\
\text { in plant }\end{array}$ & $\begin{array}{lr}\text { ant } & 3-39 \\
\text { ant } & -42\end{array}$ & $\begin{array}{l}218 \\
207\end{array}$ & $\begin{array}{l}125 \\
158\end{array}$ & $\begin{array}{l}343 \\
365\end{array}$ \\
\hline \multirow{2}{*}{$\begin{array}{l}\text { Mutants without } \\
\text { anthocyanin in } \\
\text { plant }\end{array}$} & $\begin{array}{l}\text { ant 2-Alva } \\
\text { ant }-41\end{array}$ & $\begin{array}{l}174 \\
205\end{array}$ & $\begin{array}{l}220 \\
143\end{array}$ & $\begin{array}{l}394 \\
348\end{array}$ \\
\hline & $\begin{array}{l}\text { ant }-43 \\
\text { ant } 13-13\end{array}$ & $\begin{array}{r}172 \\
1\end{array}$ & $\begin{array}{r}133 \\
4\end{array}$ & $\begin{array}{r}305 \\
5\end{array}$ \\
\hline
\end{tabular}


Table VI

Proanthocyanidin content of the grains in different ant mutants and their mother varieties in 1973.

\begin{tabular}{|c|c|c|}
\hline Category & Genotypes & $\begin{array}{l}\text { Proanthocyanidin } \mathrm{mg} / 100 \mathrm{~g} \\
\text { dry weight (HARRIS and RICKETTS) }\end{array}$ \\
\hline Wild types & Foma, Bonus, Kristina & $161,202,217$ \\
\hline $\begin{array}{l}\text { Mutants with increased } \\
\text { amount of anthocyanin }\end{array}$ & $\begin{array}{l}\text { ant-1301,-1103,-1102,-1101, } \\
\quad-1201,-1104,-1106\end{array}$ & $\begin{array}{l}248,245,228,223 \\
175,174,150\end{array}$ \\
\hline $\begin{array}{l}\text { Mutants with slightly } \\
\text { increased amount of } \\
\text { anthocyanin }\end{array}$ & ant-1105,-1204,-1203,-1202 & $181,181,169,154$ \\
\hline $\begin{array}{l}\text { Mutants with reduced } \\
\text { amount of anthocyanin }\end{array}$ & $\begin{array}{ll}\text { ant } & 3-5,3-8 \\
& 4-11,4-16,4-17,4-28 \\
\Rightarrow & 4-31,4-32,4-37,4-40 \\
\Rightarrow & 5-9,5-18,5-24 \\
\Rightarrow & 6-33,6-38 \\
\Rightarrow & 7-12 \\
\Rightarrow & 8-21 \\
\Rightarrow & 9-29 \\
\Rightarrow & 10-30 \\
\Rightarrow & 11-34 \\
\Rightarrow & 12-35 \\
\Rightarrow & 14-36 \\
" & 15-19 \\
" & 16-22 \\
" & -3,-14\end{array}$ & $\begin{array}{l}269,217 \\
178,144,150,190, \\
144,153,207,173 \\
202,185,182 \\
168,209 \\
197 \\
165 \\
169 \\
202 \\
176 \\
162 \\
171 \\
168 \\
179 \\
218,169\end{array}$ \\
\hline Mutants without anthocyanin & $\begin{array}{l}\text { ant } 1-1,1-2,1-4 \\
" 2-15,2-20,2-23,2-25 \\
" 2-26,2-27,2 \text {-Alva, } 2 \text {-Balder }\end{array}$ & $\begin{array}{l}195,180,208 \\
191,146,171,161 \\
156,155,-,-\end{array}$ \\
\hline Mutant without anthocyanin & ant 13-13 & 3 \\
\hline
\end{tabular}

anthocyanin in the plant 4 had a slightly elevated amount of proanthocyanidin, whereas 3 contained as much as the wild types. Disregarding mutant ant 13-13 no clear difference can be discovered among the mutants with slightly increased or reduced amounts of anthocyanin or those without anthocyanin. The mutants also do not differ from the wild types. A remarkable constant amount of proanthocyanidin in the grain emerges from the survey of these mutants.

\section{DISCUSSION}

Most higher plants posses the potential to form anthocyanidin under appropriate metabolic conditions. The anthocyanidin pigmen- tation may only become visible at a certain stage of development for example during ripening of the fruit. In barley the anthocyanin pigmentation in the stem, auricles, awns and lemmas culminates just before the plant turns yellow. In ripe barley there is usually no visible anthocyanin in the grains except for varieties with blue or purple grains. Comparing different genotypes there is no correlation between the amount of anthocyanin in the barley plant or grain and the amount of proanthocyanidin in the ripe grains of the same plant.

The variation in proanthocyanidin content among the different ant mutants was with the exception of ant 13-13 small, not exceeding a factor of 2. Other surveys for the content of proanthocyanidins and catechins in different 
barley varieties including anthocyanin-free ones have revealed likewise little variation in proanthocyanidin and catechin content $(9,14)$.

It is generally considered that proanthocyanidin containing plants can form anthocyanidin and the anthocyanidin formation may occur when the supply of biological reductant is cut off and the intermediate flav-3-en-3-ol is diverted by oxidation to form anthocyanidins (6). Frequently an inverse relationship between the synthesis of anthocyanin and the synthesis of proanthocyanidin has been reported (8). Genetic blocking of anthocyanin synthesis in barley does not lead to an automatic proanthocyanidin elevation. One mutant has been identified, which is blocked in both proanthocyanidin and anthocyanidin synthesis. It will be of interest if a mutant blocked in proanthocyanidin synthesis but not in anthocyanin synthesis can be isolated.

\section{ACKNOWLEDGEMENTS}

I am indebted to professor DITER vON WETTSTEIN for suggesting the project and for help to prepare the manuscript. I thank Mrs. UDDA LUNDQvisT and professor AKE GUSTAFSSON for seeds of the different mutant lines.

\section{REFERENCES}

1. Ahnström, G. \& L. Ehrenberg: Dosimetry of mixed meutron-gamma radiations in the Stockholm reactor, R-1. Proc. Symp. on selected topics in radiation dosimety IAEA, Vienna p.603 (1961)

2. DADIC, M. \& N. M. MorRison: Analytical methods for polyphenols in brewing III. Simultaneous determination of anthocyanogens and catechins (tanninogens) in brewing materials. Am. Soc. Brew. Chem. Proc. 1972, 50-56 (1972)

3. EHRENBERG, L.: Ionizing radiations: mechanism of action and dosimetry. Act. Agric. Scand. 4, 365-395 (1954)

4. Harborne, J. B.: Flavonoids. In: Phytochemistry Vol. 2. L. P. MiLLER, ed., Van Nostrand-Reynold Co., pp. 364-371 (1973)
5. HARRIS, G. \& R. W. RICkETTS: Beer haze - the problem and a solution. Eu. Bre. Con. Proc. Cong., Rome, 1959, 290-302 (1959)

6. JACQues, D., C. T. OpIE, L. J. Porter \& E. Haslam: Plant proanthocyanidins. Part 4. Biosynthesis of procyanidins and observations on the metabolism of cyanidin in plants. J. C. S. Perkin I, pp. 1637-1643 (1977)

7. Jende-Strid, B. \& U. LUNdQvist: Diallelic tests of anthocyanin-deficient mutants. Barley Genetics Newsletter 8, in press (1978)

8. McClure, J. W.: Physiology and functions of flavonoids. In: The Flavonoids. J. B. Harborne, T. J. Mabry \& H. Mabry eds., Chapman and Hall, London, pp. 970-1055 (1975)

9. McFarlane, W. D. \& P. T. Sword: Determination of anthocyanogens, III. Analysis of barley and malt. J. Inst. Brew. 68, 344-350 (1962)

10. Mullick, D. B.: Thin layer chromatography of anthocyanidins. I. Techniques and solvents for two-dimensional chromatography. J. Chromatog. 39, 291-301 (1969)

11. Mullick, D. B. \& V. C. BrinCK: Localization of anthocyanins by peeling the investments of the barley caryopsis. Crop. Science 6, 204-206 (1966)

12. Mullick, D. B., D. G. Faris, V. C. Brinck \& R. M. ACHESON: Anthocyanins and anthocyanidins of the barley pericarp and aleurone tissues. Canad. J. Plant. Sci. 38, 445-456 (1958)

13. Nүвом, N.: Thin layer chromatographic analysis of anthocyanidins. Physiol. Plant. 17, 157-164 (1964)

14. Pollock, J. R. A., A. A. Pool \& T. Reynolds: Anthocyanogens in barley and other cereals and their fate during malting. J. Inst. Brew. 66, 389. 394 (1960)

15. Swain, T. \& F. Hillis: The phenolic constituents of Prunus domestica. I. The quantitative analysis of phenolic constituents. J. Sci. Food Agric. 10, 63-68 (1959)

16. Weinges, K., W. Bähr, W. Ebert, K. Goritz \& H.-D. MARX: Die dimeren Proanthocyanidine. In Fortschritte der Chemie organischer Naturstoffe, Vol. 27. Springer Verlag, Wien, pp. 234-245 (1969)

17. Wettstein-KNowles, P. von: Mutations affecting anthocyanin synthesis in the tomato II. Physiology. Hereditas, 61, 255-275 (1969)

18. Wettstein, D. von, B. Jende-Strid, B. AhrenstLARSEN \& J. A. SøRENSEN: Biochemical mutant in barley renders chemical stabilization of beer superfluous. Carlsberg Res. Commun. 42, 341351 (1977) 